\title{
Cardiac echinococcosis
}

\author{
Surgical treatment and results
}

During the last 15 years, eight patients with a diagnosis of hydatid cysts of the heart and one patient with a diagnosis of alveolar hydatid disease with intracardiac parasitic thrombus underwent successful operation at La Pitié Hospital. Only five cases had symptoms, and the remaining four cases were diagnosed incidentally. Serologic tests achieved a variety of results and were not determinant. All patients were examined with echocardiography and angiography, and almost all patients underwent magnetic resonance scanning. Sternotomy was the approach used, and all patients underwent operation with cardiopulmonary bypass. Surgical treatment included puncture and aspiration of the cyst content, previous sterilization with hypertonic saline solution, and excision of the cyst with closure of the cavity in seven patients with different concomitant procedures. No case of intraoperative rupture was reported, and the only complication was an atrioventricular block in a patient with a cyst of the left ventricular wall invading the intreventricular septum. There was no operative mortality, and only one late death was observed. No recurrences or associated complications were reported in the late followup. (J ThoraC Cardiovasc Surg 1994;107:184-90)

A. Miralles, MD, L. Bracamonte, MD, A. Pavie, MD, V. Bors, MD, G. Rabago, MD,

I. Gandjbakhch, MD, and C. Cabrol, MD, Paris, France

$\mathrm{H}$ ydatid cyst of the heart is an uncommon lesion. ${ }^{1}$ Hydatidosis, a parasitic infection caused by Echinococcus granulosus, is a widely known zoonosis. The life cycle of this cestode/tapeworm involves dogs and other canids as definitive hosts and domestic and wild ungulates, usually sheep, as intermediate hosts. Human beings are only incidental intermediate hosts of this parasitic agent. The infection, often acquired in childhood during play with infected dogs, is most common in the sheep-raising areas of the world.

In human beings, the most frequent locations of the hydatid cysts are the liver (in more than $65 \%$ of cases) and the lungs (25\%). A mean of only about $0.5 \%$ to $2 \%$ of cases of hydatid cysts are located in the heart. ${ }^{1}$

From the Department of Cardiovascular Surgery, La Pitié Hospital, Paris, France.

Received for publication Nov. 6, 1992.

Accepted for publication March 19, 1993.

Address for reprints: Albert Miralles, MD, Department of Cardiovascular Surgery, La Pitié Hospital, 83 Bd. de l'Hôpital 75013 Paris, France.

Copyright $\stackrel{(\odot)}{ } 1994$ by Mosby-Year Book, Inc.

$0022-5223 / 94 \$ 1.00+.10 \quad \mathbf{1 2} / \mathbf{1} / \mathbf{4 7 9 4 4}$
Because of the continuous growing of the cysts, the surrounding tissues and cardiac structures become progressively affected, leading to the impairment of the hemodynamic function of the heart. Direct sterilization and surgical excision have been proved to be the best treatment of hydatid cysts of the heart. In this article, we report our clinical and surgical experience on the treatment of the cardiac hydatidosis.

\section{Patients and methods}

Between 1971 and 1987, eight patients with hydatid cysts of the heart and one patient with alveolar hydatid disease and parasitic cardiac thrombosis underwent surgical excision at the Department of Cardiovascular Surgery of La Pitié Hospital in Paris, France. There were five male and four female patients, ranging in age from 4 to 63 years with a mean age of $27 \pm 17$ years. Six of them were born in North Africa.

The diagnoses were incidental in four patients $(44.4 \%)$, the remaining patients had a variety of symptoms, especially cough and chest pain (Table I).

Seven of the patients were in New York Heart Association functional class I, and two were in class II. Physical examination did not provide much evidence of disease, and in only two cases did we find pathologic cardiac murmurs. Another patient had ventilatory alterations, and one other had a palpable mass in the right hypochondrium. 




Fig. 1. Bulge on the left border of the heart.

Table I. Symptomatology

\begin{tabular}{lcc}
\hline & $\begin{array}{c}\text { No. of } \\
\text { patients }\end{array}$ & Percentage \\
\hline Without symptoms & 4 & 44 \\
With symptoms & 5 & 56 \\
Cough & 3 & 60 \\
Chest pain & 4 & 80 \\
Fever & 1 & 20 \\
Hemoptysis & 1 & 20 \\
Dyspnea & 2 & 40 \\
Cerebral accident & 1 & 20 \\
\hline
\end{tabular}

Chest roentgenograms showed a clear deformation of the medium arch of the cardiac silhouette in most of the cases $(77.7 \%$ ) (Fig. 1). Mediastinic and pulmonary calcifications were also observed in two cases, pulmonary cysts in one case, and images considered as masses of the pulmonary parenchyma in one case.

The electrocardiogram usually showed modifications on the ST segment and T wave, similar to those observed in patients with coronary artery disease and subepicardic ischemia. Other observed modifications were negative $Q$ wave, large QRS space, and $\mathrm{T}$ wave inversions.

All patients were examined with cardiac echography (Fig. 2) with the following diagnoses: cardiac cysts in four patients (44.4\%), tumor of unidentified origin in four patients $(44.4 \%)$, and the normal echocardiographic characteristics in one patient $(11.2 \%)$.

Catheterization was performed in all cases, with coronary angiography in two cases. This examination evaluated seven cases as positive for disease and included findings such as high recorded pressures in the right cavities, calcification of the left ventricular wall, external compression of the right ventricle, mass in the ventricular surface, left ventricular cystic image, and substraction image of the left ventricle. Coronary angiography was performed in two patients, showing displacements and anatomic disturbances of the coronary arteries caused by the
Table II. Associated organs involved

\begin{tabular}{lcc}
\hline & $\begin{array}{c}\text { No. of } \\
\text { patients }\end{array}$ & Percentage \\
\hline Hepatic cyst & 5 & 56 \\
Pulmonary cyst & 3 & 33 \\
Kidney cyst & 1 & 11 \\
Costal cyst & 1 & 11 \\
\hline
\end{tabular}

cysts. In one case, a circular blush was evident (Fig. 3). Other complementary exploratory techniques used were scintigraphy in two cases and computed tomography and nuclear magnetic resonance imaging in four cases (Fig. 4).

Serologic tests (agglutination) were not conclusive because the results were variable. In four cases $(45 \%)$ the test was positive for disease, in two cases (22\%) it was negative, in one case $(11 \%)$ it was unspecific, and in two cases $(22 \%)$ the test was not done. Noncardiac cysts were also observed in five patients (Fig. 5). Other organs involved are indicated in Table II.

Eight of the nine patients underwent operation with the preoperative diagnosis of cardiac cyst; during the operation in one patient in whom a right atrial myxoma was suspected, a tumoral mass consisting of a thrombuslike structure, ruptured vesicles, and cystic layers was removed from the right atrium.

In all cases, the operation was performed with medial sternotomy and cardiopulmonary bypass. Mean cardiopulmonary bypass time was $48 \pm 20$ minutes ranging between 30 and 77 minutes. In four patients, cysts were removed while the patient underwent induced electrical cardiac fibrillation and mild hypothermia; in the remaining five patients, the excision was done after aortic clamping with moderate hypothermia and cardioplegia.

The site of implantation of the cysts was the left ventricular wall in seven cases, the right ventricular wall in one case, and the right atrium in one case. With the exception of one case in which two cysts were discovered, the cysts were isolated in all patients.

All cysts were systematically sterilized. Complete and rapid sterilization of the cysts was performed by injection or instilla- 


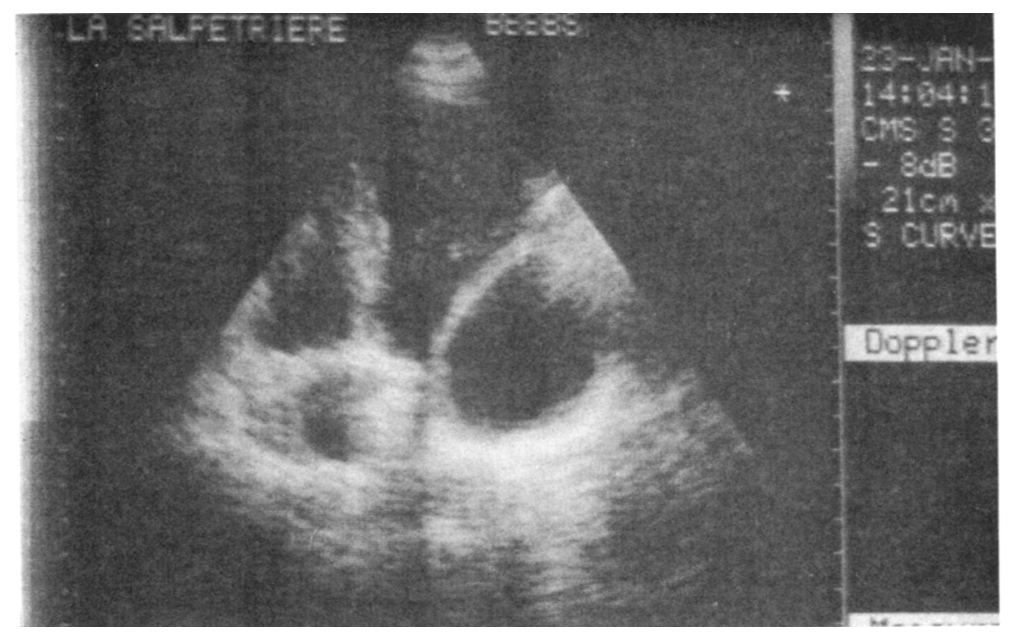

Fig. 2. Bidimensional echocardiography: intrapericardial mass involving the ventricular wall.
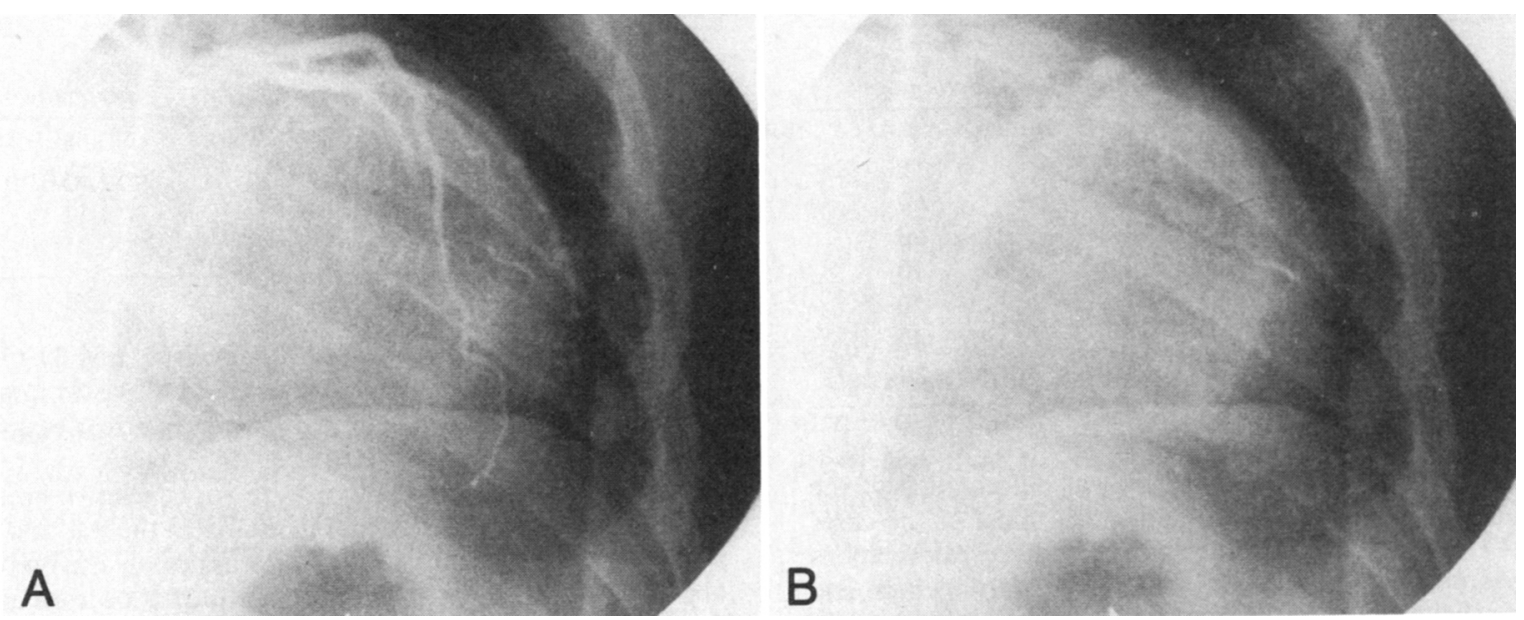

Fig. 3. A, Coronary angiography showing the displacement of the coronary arteries without luminal obstruction. B, In a later phase, a circular blush can be observed, clearly depicting the cyst.

tion of hypertonic saline solution. After sterilization, cysts were enucleated, and the cavity was closed in seven cases by obliteration, plication, or both (Fig. 6). The cavity was let unclosed in one patient. In only one case was a Dacron patch implantation needed to close a ventricular septal defect created after excision of a left ventricular cyst near the septal wall.

\section{Results}

The postoperative course was satisfactory in all nine patients. The only complication was a complete atrioventricular block in one patient with a cyst invading the interventricular septum. No operative mortality occurred, and only one case of late mortality of unknown causes occurred. With a follow-up of 1798 patient/days (total 16,184 days), no recurrences or surgically related complications were found.

\section{Discussion}

Cardiac involvement of hydatid cyst is an uncommon lesion if compared with hepatic or pulmonary hydatidosis. The reported prevalence is about $0.5 \%$ to $2 \% .{ }^{1,2}$

Human echinococcosis is caused most commonly by Echinococcus granulosus. ${ }^{3}$ Another type is Echinococcus multilocularis ${ }^{4}$ the agent of alveolar hydatid disease. Human beings are only incidental hosts by contamination from contact with animals.

After infection, the embryo usually reaches the myo- 


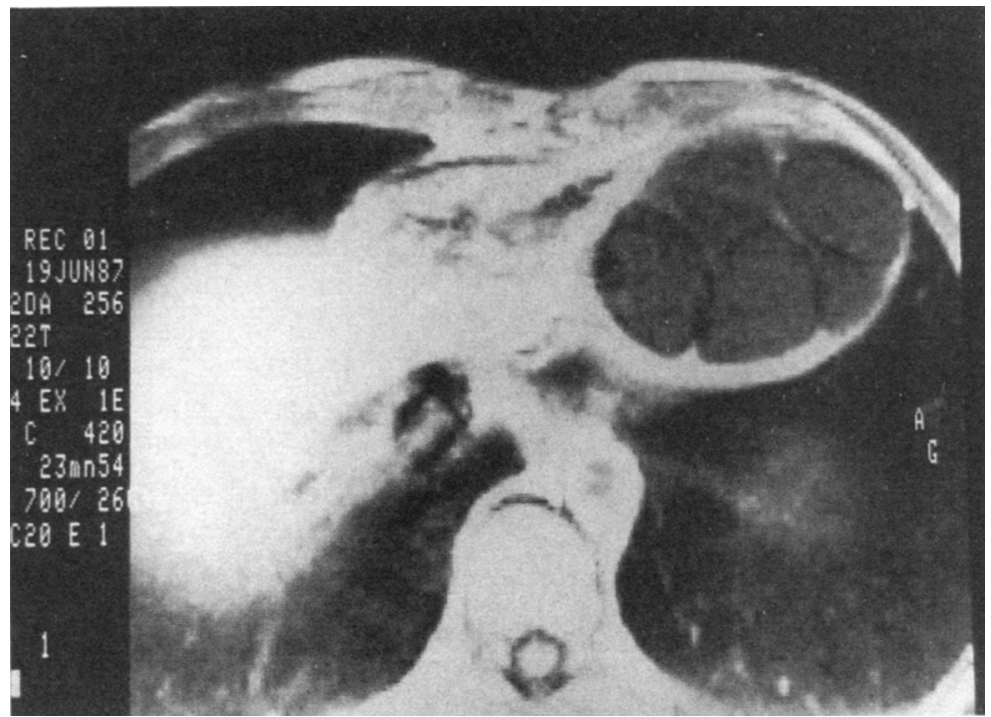

Fig. 4. Magnetic resonance imaging: axial view showing a multilobed mass of the left ventricle.

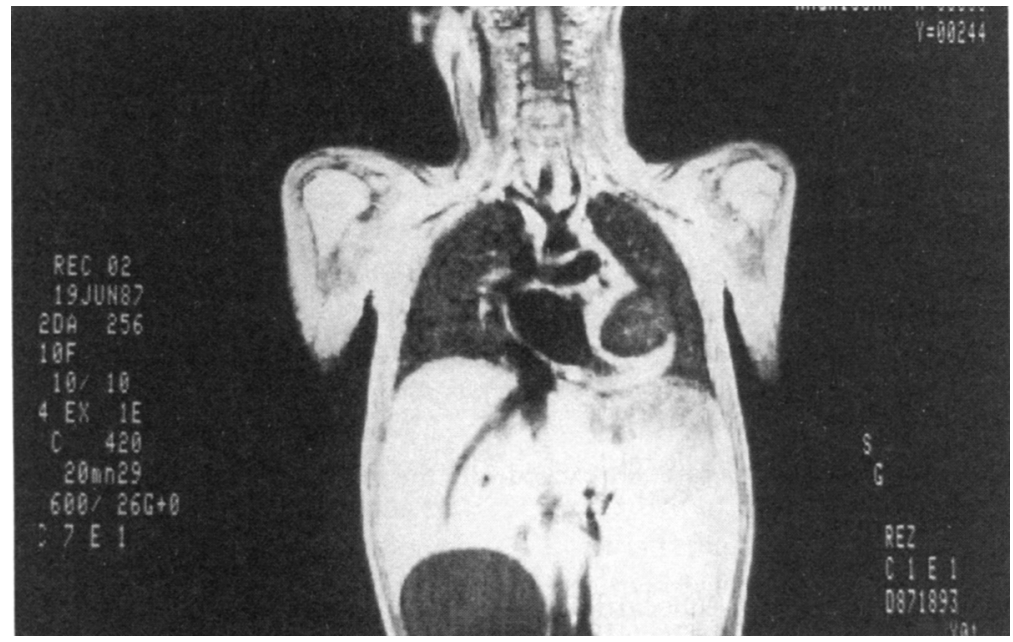

Fig. 5. Multiple organ involvement is evidenced by magnetic resonance imaging. In a frontal view, a multilobed cyst of the heart is associated with a large hepatic cyst in one of our young patients.

cardium via coronary circulation from the left side of the heart. The cyst is then formed within a period of 1 to 5 years. Myocardial reaction consists of a fibrous adventitial pericyst layer surrounding the laminated membrane. $^{5}$

A wide variation in age has been reported with this condition, without prevalence for age. Some reports ${ }^{1,6}$ indicate that cardiac hydatidosis tends to manifest in individuals over the age of 20 years; however, several cases have been reported in younger patients. In spite of our experience, it seems that a prevalence for infection exists in male patients.

Probably only $10 \%$ of cases of hydatidosis have clinical manifestations. ${ }^{7}$ It is widely known that in cystic hydatid disease, the severity and nature of signs and symptoms are extremely variable and rarely pathognomonic, and different clinical syndromes may be present (Table II).

The disease should be suspected in patients from sheep-raising areas, especially if they have signs of cardi- 


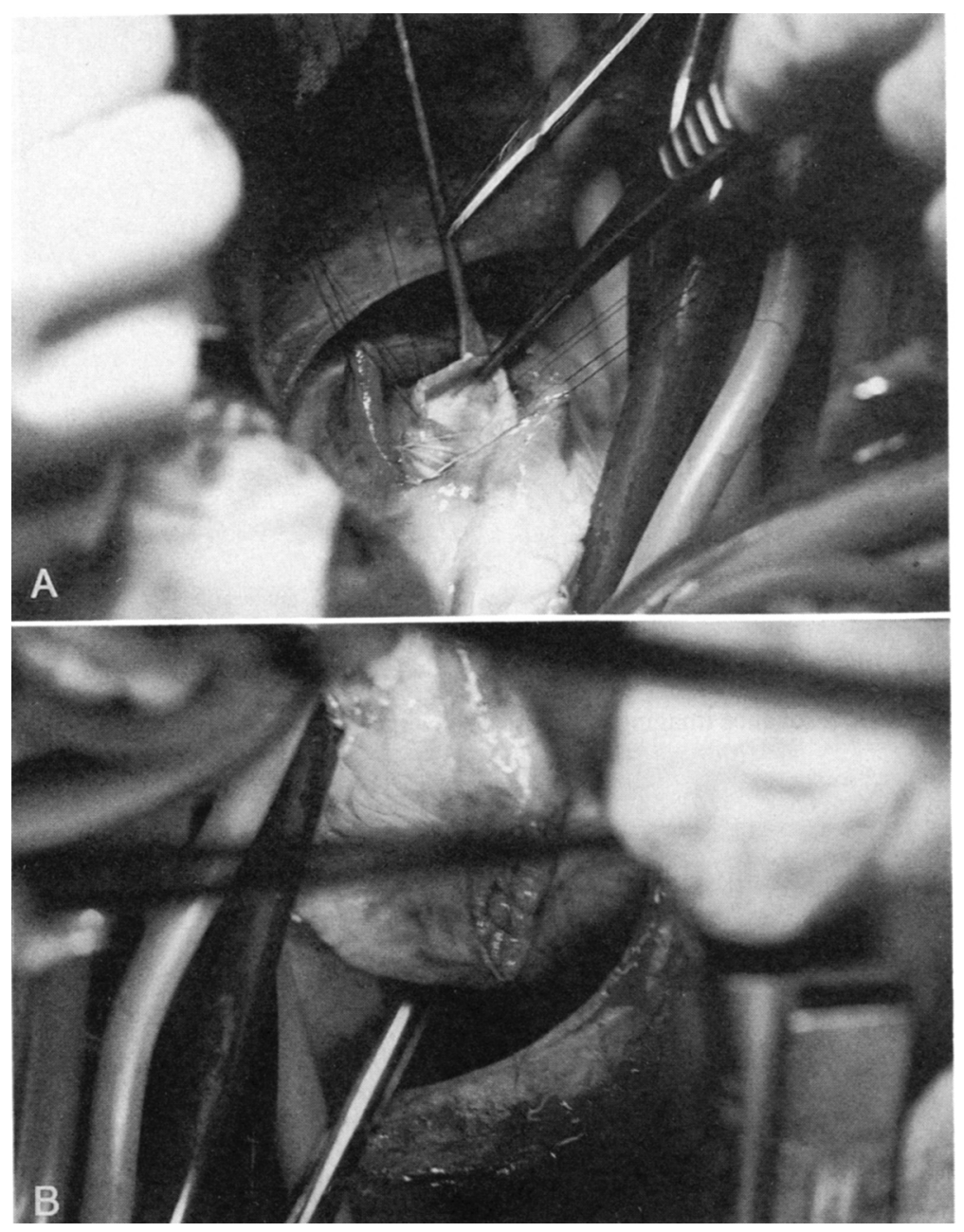

Fig. 6. A, After sterilization, the cyst is carefully excised with the surrounding layers. B, The cavity is plicated to reinforce the myocardial wall.

ac tumor, or when a chest roentgenogram or echocardiogram reveals a mass in relation with the cardiac silhouette.

The most common manifestation observed is chest pain or precordialgia. In our series we found cough and chest pain in three patients and precordalgia in two others. Two patients had embolism, and two others had congestive heart failure. Other clinical features observed were valvular syndrome with the clinical simulation of a mitral, pulmonary, or tricuspid stenosis or regurgitation ${ }^{8,9}$ and ischemic syndrome. ${ }^{10}$ The ischemic syndrome is of utmost importance because total obstruction of coronary vessels by the cysts has been reported ${ }^{11,12}$ with the need for surgical coronary revascularization. Electrocardiographic changes, such as myocardial infarction, arrhythmias, bundle branch conduction disturbances, and sudden cardiac arrest, have been observed also.
The skin test of Casoni is usually positive for disease in these cases but lacks both sensitivity and specificity. ${ }^{13}$ Its use has been recently discussed because it can generate the sensitization of the patients. Serologic tests have a higher sensitivity and specificity, but they are positive in only approximately $60 \%$ of pulmonary and $90 \%$ of hepatic lesions. The most useful tests are latex agglutination test and immunoelectrophoresis. ${ }^{13,14}$

Echocardiography is the method of choice for the diagnosis of cardiac cysts. ${ }^{15}$ Two-dimensional echocardiography allows the differentiation of a cyst from a solid mass. In our series, it was only in one case that the echocardiographic imaging revealed a solid mass that was assumed to be a right atrial myxoma, although at operation the mass turned out to be a larval proliferative lesion of Echinococcus multilocularis.

Nuclear magnetic resonance imaging also provides 
valuable information for the diagnosis, with clear evaluation of tumor extension and tissue involvement. ${ }^{16}$

We believe, as do other authors, ${ }^{17-19}$ that catheterization and coronary angiography are helpful tools in patients with hydatid cysts of the heart. Ventriculography can be useful to determine the intraventricular location of the cysts. Coronary angiography is the only way to evaluate the coronary vessels, and, in late sequences of angiography, the anatomic site and size of the cyst may be depicted in the myocardium (Fig. 3).

In our experience, seven patients had electrocardiographic alterations compatible with those of subepicardial ischemia and necrosis. Angiocardiography was performed in six patients, showing alterations of the interventricular septum and the right and the left ventricular free walls. In two cases a coronary angiography showed the displacement of coronary artery branches without obstruction. Because some cases of coronary artery obstruction by hydatid cysts have been reported in other series, ${ }^{11,12}$ we think that coronary angiography should be performed in all patients in whom cardiac hydatidosis is suspected to determine whether the electrocardiographic changes usually observed represent a direct menace for the myocardium. Regardless of the invasive nature of these techniques, we believe they are very helpful for the operative strategy, allowing the surgeon to carry out better myocardial protection or coronary revascularization if required.

In two patients (one was an 8-year-old child), the surgical excision was performed while the patient was under mild hypothermia and induced electrical fibrillation. In accordance with recent tendencies, we used moderate hypothermia with aortic crossclamping and infusion of cardioplegic solution in the last five patients. We think this technique is safer, one of the reasons being that there is a great variability in the time and type of operation required for excision of cysts, depending on the degree of myocardial involvement. ${ }^{17}$ In some cases, smaller, concomitant cysts can be discovered during operation, which leads to the prolongation of both the ischemic and cardiopulmonary bypass times. Partially because of these delays, our cardiopulmonary bypass times had a wide range ( 30 to 77 minutes).

One of the difficulties in the removal of the hydatid cysts is the extreme fragility of the outer membrane and the risk of uncontrolled rupture with leakage of content into the pericardium or systemic circulation. If this happens or when a ruptured old cyst is discovered, it is mandatory to perform an enlarged pericardectomy. ${ }^{19} \mathrm{Com}$ plete and rapid sterilization of the cyst content must be performed with the injection or instillation of such agents as $2 \%$ formalin, $0.5 \%$ silver nitrate solution, ${ }^{21} 30 \%$ hypertonic saline solution, ${ }^{19} 1 \%$ iode solution, and $5 \%$ cetimide solution. In our experience, we used hypertonic saline solution without adverse effects. If total excision of the cyst wall is not feasible because of the proximity of cardiac structures, the remaining cavity should be closed because complications have been observed in cases of simple drainage or marsupialization of the cavities. Closure of the cyst by obliteration and plication of the cavity was performed in six of our patients to provide a higher rigidity to the weakened cardiac wall (Fig. 6).

Operative mortality is very low, and the postoperative evolution is usually satisfactory and uncomplicated. ${ }^{17,18}$ Surgical excision is the best treatment, because no effective chemotherapy against larval cestode infections has been developed yet. However, some authors ${ }^{17}$ advocate the use of routine medical therapy as a supplement to the operation. Since 1975 , mebendazole ${ }^{7}$ has been used with poor results. The usual dose is 30 to $40 \mathrm{mg} / \mathrm{kg}$ per day for 10 to 12 months. In recent years, new drugs such as flubendazole and albendazole have been used. ${ }^{7}$

During the follow-up, echocardiographic and serologic controls are advisable to detect recurrences or other associated complications.

Di Bello and associates ${ }^{22}$ reported four sudden deaths in patients who underwent operation years before, two of whom had ruptured cysts in the pericardium during the operation. The cause of death might be related to the rupture of cysts that were not discovered at operation or the proliferation of particles of cysts ruptured during surgical manipulation. Other causes could be tachyarrhythmias originating from the fibrous zone of excision. In our follow-up, sudden death occurred in a patient in whom a cyst involving the interventricular septum was excised 2 years before.

It is remarkable that five of our patients (55\%) had multivisceral involvement (liver, lungs, kidneys, and heart), and this finding brought us to the conclusion that the reported prevalence of cardiac hydatidosis would be higher if cardiac structures were routinely explored in patients with multiple hydatic cyst disease.

We thank Dr. C. Obi for his assistance in the editing of this paper.

\section{REFERENCES}

1. Dighiero J, Canabal EJ, Hazan J, Horlales JO. Echinococcus: disease of the heart. Circulation 1958;17:128-31.

2. Heyat I, Mokhtari H, Hajaliloo J, Shakibi JG. Surgical treatment of echinococcal cyst of the heart. J THORAC CardiovasC SuRg 1971;61:755-64.

3. Rausch RL. Taeniidae. In: Diseases transmitted from animals to man. Springfield, Ill: C. C. Thomas, 1975:678-707.

4. Stepien L. Cerebral cysticercosis in Poland: clinical symp- 
toms and operative results in 132 cases. J Neurosurg 1962;19:505-13.

5. Gibson DS. Cardiac hydatid cysts. Thorax 1964;19:151.

6. Popo I, Savic S. Hydatid disease of the heart. Br J Surg 1962;49:598-600.

7. Verger G. Helmintiasis histicas: Equinococosis. In: Enfermedades infecciosas. Barcelona: DOYMA SA, ed. 1988: 441-6.

8. Perez-Gomez F, Duran H, Tamames S, et al. Cardiac Echinococcosis: clinical picture and complications. $\mathrm{Br}$ Heart J 1973;35:1326-31.

9. Hazan E, Leblanc J, Robillard M, et al. Hydatid cyst of the right ventricle revealed by an acute complication: emergency exeresis with prosthetic replacement of the tricuspid valve. Chirurgie 1970;96:257-60.

10. Vestri A, Nigri A, Massi L, et al. Electrocardiographic picture of myocardial infract during echinococcosis of the heart. Boll Soc Ital Cardiol 1972;17:752-4.

11. Calamai G, Perna AM, Venturini A. Hydatid disease of the heart: report of five cases and review of the literature. Tho$\operatorname{rax} 1974 ; 29: 451-8$.

12. Urquia M, Garrido J, de los Arcos E, et al. Hidatidosis del septo interventricular. Rev Clin Esp 1975;138:521-7.

13. Munoz C, Portus M. Estudio comparativo de diversas tecnicas serologicas para el diagnostico de laboratorio de la hidatidosis. Rev Iber Parasitol 1982;(Suppl):345-58.
14. Varuela-Diaz VM, Coltorti EA, Preziosos U, Lopez-Lemes MH, Guisantes JA, Yarzabal LA. Evaluation of three immunodiagnostic test for human hydatid disease. Am $\mathbf{J}$ Trop Med Hyg 1975;24:312-9.

15. Farooki ZQ, Adelman S, Green EW. Echocardiographic differentiation of a cystic and solid tumor of the heart. Am J Cardiol 1977;39:107-11.

16. Vanjak D, Moutaoufik M, Leroy O, et al. Hydatidose cardiaque: apport de l'imagerie par resonance magnetique. Arch Mal Coeur Vaiss 1990;83:1739-42.

17. Ameli M, Mobarhan HA, Nouraii SS. Surgical treatment of hydatid cysts of the heart: report of six cases. J THORAC CARDIOVASC SuRg 1989;98:892-901.

18. Shakibi JG, Safavian MH, Azar H, Siassi B. Surgical treatment of echinococcal cyst of the heart: report of two cases and review of the world literature. J THORAC CARDIOVASC SURG 1977;74:941-6.

19. Malmejac J, Hovel J, Metras D, et al. Hydatid cyst of the heart. Chirurgie 1970;96:261-7.

20. Saidi F, Nazarian I. Surgical treatment of hydatid cysts by freezing of cyst wall and instillation of 0.5 percent silver nitrate solution. N Engl J Med 1971;284:1346-50.

21. Di Bello R, Sadi I, Esteves S. Abnormal precordial pulsation in cardiac echinococcosis. J THORAC CARdIOvasC SURG 1967;53:366-70. 